\title{
Strong convergence theorems for uniformly $L$-Lipschitzian asymptotically pseudocontractive mappings in Banach spaces
}

\section{Zhiqun Xue* and Guiwen LV}

"Correspondence:

xuezhiqun@126.com Department of Mathematics and Physics, Shijiazhuang Tiedao University, Shijiazhuang, 050043, P.R. China

\begin{abstract}
In this paper, we establish some strong convergence theorems of the modified Ishikawa and Mann iterations with errors of uniformly L-Lipschitzian asymptotically pseudocontractive mappings in real Banach spaces. Our results not only provide the new proof method, but also extend the known corresponding results given in (Chang in Proc. Am. Math. Soc. 129:845-853, 2001; Chang et al. in Appl. Math. Lett. 22:121-125, 2009; Goebel and Kirk in Proc. Am. Math. Soc. 35:171-174, 1972; Ofoedu in J. Math. Anal. Appl. 321:722-728, 2006; Schu in J. Math. Anal. Appl. 158:407-413, 1991). In order to get some applications of our results, we also provide specific examples.
\end{abstract}

MSC: $47 \mathrm{H} 09 ; 47 \mathrm{H} 10$

Keywords: uniformly L-Lipschitzian mapping; asymptotically pseudocontractive mapping; fixed point; real Banach space

\section{Introduction and preliminaries}

Let $E$ be a real Banach space and let $J$ denote the normalized duality mapping from $E$ into $2^{E^{\circ}}$ defined by

$$
J(x)=\left\{f \in E^{*}:\langle x, f\rangle=\|x\|^{2}=\|f\|^{2}\right\}
$$

for all $x \in E$, where $E^{*}$ denotes the dual space of $E$ and $\langle\cdot, \cdot\rangle$ denotes the generalized duality pairing, respectively. The normalized duality mapping $J$ has the following properties:

(1) $J$ is an odd mapping, i.e., $J(-x)=-J(x)$.

(2) $J$ is positive homogeneous, i.e., for any $\lambda>0, J(\lambda x)=\lambda J(x)$.

(3) $J$ is bounded, i.e., for any bounded subset $A$ of $E, J(A)$ is a bounded subset of $E^{*}$.

(4) If $E$ is smooth (or $E^{*}$ is strictly convex), then $J$ is single-valued.

In the sequel, we denote the single-valued normalized duality mapping by $j$. In a Hilbert space $H, j$ is the identity mapping.

Let $D$ be a nonempty closed convex subset of $E$. A mapping $T: D \rightarrow D$ is said to be asymptotically nonexpansive with a sequence $\left\{k_{n}\right\} \subset[1,+\infty)$ and $\lim _{n \rightarrow \infty} k_{n}=1$ if, for all 
$x, y \in D$,

$$
\left\|T^{n} x-T^{n} y\right\| \leq k_{n}\|x-y\|
$$

for all $n \geq 1$. The mapping $T$ is said to be asymptotically pseudocontractive with a sequence $\left\{k_{n}\right\} \subset[1,+\infty)$ and $\lim _{n \rightarrow \infty} k_{n}=1$ if, for any $x, y \in D$, there exists $j(x-y) \in J(x-y)$ such that

$$
\left\langle T^{n} x-T^{n} y, j(x-y)\right\rangle \leq k_{n}\|x-y\|^{2}
$$

for all $n \geq 1$. Furthermore, the mapping $T$ is said to be uniformly L-Lipschitzian if, for any $x, y \in D$, there exists a constant $L>0$ such that

$$
\left\|T^{n} x-T^{n} y\right\| \leq L\|x-y\|
$$

for all $n \geq 1$.

It is easy to see that if $T$ is an asymptotically nonexpansive mapping, then it is both asymptotically pseudocontractive and uniformly $L$-Lipschitzian. The converse is not true in general. Therefore, it is interesting to study these mappings in fixed point theory and its applications. In fact, the asymptotically nonexpansive and asymptotically pseudocontractive mappings were first introduced by Goebel-Kirk [1] and Schu [2], respectively. Since then, some authors have studied several iterative sequences for asymptotically nonexpansive and asymptotically pseudocontractive mappings in Hilbert spaces and Banach spaces (see [3-11]).

In [2], Schu proved the following theorem.

Theorem 1.1 [2] Let $H$ be a Hilbert space, $K$ be a nonempty bounded closed convex subset of $H$ and $T: K \rightarrow K$ be a completely continuous, uniformly L-Lipschitzian and asymptotically pseudocontractive mapping with a sequence $\left\{k_{n}\right\} \subset[1,+\infty)$ satisfying the following conditions:

(a-1) $k_{n} \rightarrow 1$ as $n \rightarrow \infty$;

(a-2) $\sum_{n=1}^{\infty}\left(q_{n}^{2}-1\right)<\infty$, where $q_{n}=2 k_{n}-1$.

Suppose further that $\left\{\alpha_{n}\right\}$ and $\left\{\beta_{n}\right\}$ are two sequences in $[0,1]$ such that $\epsilon<\alpha_{n}<$ for all $n \geq 1$, where $\epsilon>0$ and $b \in\left(0, L^{-2}\left[\left(1+L^{2}\right)^{1 / 2}-1\right]\right)$. For any $x_{1} \in K$, let $\left\{x_{n}\right\}$ be an iterative sequence defined by

$$
x_{n+1}=\left(1-\alpha_{n}\right) x_{n}+\alpha_{n} T^{n} x_{n}
$$

for all $n \geq 1$. Then $\left\{x_{n}\right\}$ converges strongly to a fixed point of $T$ in $K$.

In [12], Chang extended above Theorem 1.1 to the setting of real uniformly smooth Banach spaces and proved the following.

Theorem 1.2 [12] Let E be a uniformly smooth Banach space, $K$ be a nonempty bounded closed convex subset of $E$ and $T: K \rightarrow K$ be an asymptotically pseudocontractive mapping with a sequence $\left\{k_{n}\right\} \subset[1,+\infty), \lim _{n \rightarrow \infty} k_{n}=1$ and $F(T) \neq \emptyset$, where $F(T)$ is the set of fixed points of $T$ in $K$. Let $\left\{\alpha_{n}\right\}$ be a sequence in $[0,1]$ satisfying the following conditions:

(a-1) $\alpha_{n} \rightarrow 0$ as $n \rightarrow \infty$;

(a-2) $\sum_{n=0}^{\infty} \alpha_{n}=\infty$. 
For any $x_{0} \in K$, let $\left\{x_{n}\right\}$ be an iterative sequence defined by

$$
x_{n+1}=\left(1-\alpha_{n}\right) x_{n}+\alpha_{n} T^{n} x_{n}
$$

for all $n \geq 0$. If there exists a strictly increasing function $\Phi:[0,+\infty) \rightarrow[0,+\infty)$ with $\Phi(0)=$ 0 such that

$$
\left\langle T^{n} x-x^{*}, j\left(x-x^{*}\right)\right\rangle \leq k_{n}\left\|x-x^{*}\right\|^{2}-\Phi\left(\left\|x-x^{*}\right\|\right)
$$

for all $x \in K$ and $n \geq 0$, where $x^{*} \in F(T)$, then $x_{n} \rightarrow x^{*}$ as $n \rightarrow \infty$.

In [13], Ofoedu extended Theorem 1.2 in a uniformly smooth Banach space to the setting of arbitrary real Banach spaces and dropped the boundedness assumption in Theorem 1.2.

Theorem 1.3 [13] Let E be a real Banach space, $K$ be a nonempty closed convex subset of $E$ and $T: K \rightarrow K$ be a uniformly L-Lipschitzian asymptotically pseudocontractive mapping with a sequence $\left\{k_{n}\right\} \subset[1,+\infty), \lim _{n \rightarrow \infty} k_{n}=1$ and $x^{*} \in F(T)$. Let $\left\{\alpha_{n}\right\}$ be a sequence in $[0,1]$ satisfying the following conditions:

(a-1) $\sum_{n=0}^{\infty} \alpha_{n}=\infty$;

(a-2) $\sum_{n=0}^{\infty} \alpha_{n}^{2}<\infty$;

(a-3) $\sum_{n=0}^{\infty} \alpha_{n}\left(k_{n}-1\right)<\infty$.

For any $x_{0} \in K$, let $\left\{x_{n}\right\}$ be an iterative sequence defined by

$$
x_{n+1}=\left(1-\alpha_{n}\right) x_{n}+\alpha_{n} T^{n} x_{n}
$$

for all $n \geq 0$. If there exists a strictly increasing function $\Phi:[0,+\infty) \rightarrow[0,+\infty)$ with $\Phi(0)=$ 0 such that

$$
\left\langle T^{n} x-x^{*}, j\left(x-x^{*}\right)\right\rangle \leq k_{n}\left\|x-x^{*}\right\|^{2}-\Phi\left(\left\|x-x^{*}\right\|\right)
$$

for all $x \in K$ and $n \geq 0$. Then

(1) $\left\{x_{n}\right\}$ is bounded;

(2) $\left\{x_{n}\right\}$ converges strongly to $x^{*} \in F(T)$.

Theorem 1.4 [13] Let E be a real Banach space. Let $K$ be a nonempty closed and convex subset of $E, T: K \rightarrow K$ be a uniformly L-Lipschitzian asymptotically pseudocontractive mapping with a sequence $\left\{k_{n}\right\} \subset[1,+\infty)$ with $\lim _{n \rightarrow \infty} k_{n}=1$ and $x^{*} \in F(T)$. Let $\left\{a_{n}\right\},\left\{b_{n}\right\}$ and $\left\{c_{n}\right\}$ be real sequences in $[0,1]$ satisfying the following conditions:

(a-1) $a_{n}+b_{n}+c_{n}=1$

(a-2) $\sum_{n \geq 0}\left(b_{n}+c_{n}\right)=\infty$;

(a-3) $\sum_{n \geq 0}\left(b_{n}+c_{n}\right)^{2}<\infty$;

$(\mathrm{a}-4) \sum_{n \geq 0}\left(b_{n}+c_{n}\right)\left(k_{n}-1\right)<\infty$;

(a-5) $\sum_{n \geq 0} c_{n}<\infty$.

For arbitrary $x_{0} \in K$, let $\left\{x_{n}\right\}$ be a sequence in $K$ iteratively defined by

$$
x_{n+1}=a_{n} x_{n}+b_{n} T^{n} x_{n}+c_{n} u_{n}
$$


for all $n \geq 0$, where $\left\{u_{n}\right\}$ is a bounded sequence in $K$. Suppose that there exists a strictly increasing continuous function $\Phi:[0,+\infty) \rightarrow[0,+\infty)$ with $\Phi(0)=0$ such that

$$
\left\langle T^{n} x-x^{*}, j\left(x-x^{*}\right)\right| \leq k_{n}\left\|x-x^{*}\right\|^{2}-\Phi\left(\left\|x-x^{*}\right\|\right)
$$

for all $x \in K$. Then $\left\{x_{n}\right\}_{n \geq 0}$ converges strongly to $x^{\prime \prime} \in F(T)$.

Very recently, in [14], Chang et al. proved the following theorem.

Theorem 1.5 [14] Let $E$ be a real Banach space. Let $K$ be a nonempty closed convex subset of $E, T_{i}: K \rightarrow K$ be two uniformly $L_{i}$-Lipschitzian mappings with $F\left(T_{1}\right) \cap F\left(T_{2}\right) \neq \emptyset$ and $x^{*} \in F\left(T_{1}\right) \cap F\left(T_{2}\right)$. Let $\left\{k_{n}\right\} \subset[1,+\infty)$ be a sequence with $\lim _{n \rightarrow \infty} k_{n}=1$. Let $\left\{\alpha_{n}\right\}$ and $\left\{\beta_{n}\right\}$ be two sequences in $[0,1]$ satisfying the following conditions:

(a-1) $\sum_{n=0}^{\infty} \alpha_{n}=\infty$;

(a-2) $\sum_{n=0}^{\infty} \alpha_{n}^{2}<\infty$;

(a-3) $\sum_{n=0}^{\infty} \beta_{n}<\infty$;

(a-4) $\sum_{n=0}^{\infty} \alpha_{n}\left(k_{n}-1\right)<\infty$.

For any $x_{0} \in K$, let $\left\{x_{n}\right\}$ be an iterative sequence in $K$ defined by

$$
\left\{\begin{array}{l}
x_{n+1}=\left(1-\alpha_{n}\right) x_{n}+\alpha_{n} T_{1}^{n} y_{n} \\
y_{n}=\left(1-\beta_{n}\right) x_{n}+\beta_{n} T_{2}^{n} x_{n}
\end{array}\right.
$$

for all $n \geq 0$. If there exists a strictly increasing function $\Phi:[0,+\infty) \rightarrow[0,+\infty)$ with $\Phi(0)=0$ such that

$$
\left\langle T_{i}^{n} x-x^{*}, j\left(x-x^{*}\right)\right| \leq k_{n}\left\|x-x^{*}\right\|^{2}-\Phi\left(\left\|x-x^{*}\right\|\right)
$$

for all $j\left(x-x^{*}\right) \in J\left(x-x^{*}\right)$ and $x \in K, i=1,2$, then $\left\{x_{n}\right\}$ converges strongly to $x^{*}$.

Also, some authors have studied the modified Halpern, Mann and Ishikawa iterative sequences for nonlinear mappings in Hilbert spaces and Banach spaces (see [15, 16]).

The aim of this paper is to give some strong convergence theorems for uniformly $L$-Lipschitzian and asymptotically pseudo contractive mappings in Banach spaces. Our results not only include the past ones known in [3-11], but also provide quite a different proof method.

For our main purpose, we recall some concepts and lemmas.

Definition 1.6 [17] For arbitrary $x_{1} \in D$, the sequence $\left\{x_{n}\right\}$ in $D$ defined by

$$
\left\{\begin{array}{l}
y_{n}=\left(1-b_{n}-d_{n}\right) x_{n}+b_{n} T^{n} x_{n}+d_{n} v_{n}, \\
x_{n+1}=\left(1-a_{n}-c_{n}\right) x_{n}+a_{n} T^{n} y_{n}+c_{n} u_{n}
\end{array}\right.
$$

for all $n \geq 1$ is called the modified Ishikawa iteration with errors, where $\left\{a_{n}\right\},\left\{b_{n}\right\},\left\{c_{n}\right\}$, $\left\{d_{n}\right\}$ are four real sequences in $[0,1]$ satisfying $a_{n}+c_{n} \leq 1, b_{n}+d_{n} \leq 1$ and $\left\{u_{n}\right\},\left\{v_{n}\right\}$ are any bounded sequences in $D$. 
In particular, if $b_{n}=d_{n}=0$ in (1.4), then the sequence $\left\{x_{n}\right\}$ defined by

$$
x_{n+1}=\left(1-a_{n}-c_{n}\right) x_{n}+a_{n} T^{n} x_{n}+c_{n} u_{n}
$$

for all $n \geq 1$ is called the modified Mann iteration with errors.

If $c_{n}=d_{n}=0$ in (1.4) and (1.5), then the sequence $\left\{x_{n}\right\}$ defined by

$$
\left\{\begin{array}{l}
y_{n}=\left(1-b_{n}\right) x_{n}+b_{n} T^{n} x_{n}, \\
x_{n+1}=\left(1-a_{n}\right) x_{n}+a_{n} T^{n} y_{n}
\end{array}\right.
$$

and

$$
x_{n+1}=\left(1-a_{n}\right) x_{n}+a_{n} T^{n} x_{n}
$$

for all $n \geq 1$ is called the modified Ishikawa iteration and the modified Mann iteration, respectively.

Lemma 1.7 [18] Let $E$ be a real Banach space and $J: E \rightarrow 2^{E^{*}}$ be a normalized duality mapping. Then

$$
\|x+y\|^{2} \leq\|x\|^{2}+2\langle y, j(x+y)\rangle
$$

for all $x, y \in E$ and $j(x+y) \in J(x+y)$.

Lemma 1.8 [19] Let $\left\{\delta_{n}\right\},\left\{\lambda_{n}\right\}$ and $\left\{\gamma_{n}\right\}$ be three nonnegative real sequences and $\Phi$ : $[0,+\infty) \rightarrow[0,+\infty)$ be a strictly increasing continuous function with $\Phi(0)=0$ satisfying the following inequality:

$$
\delta_{n+1}^{2} \leq \delta_{n}^{2}-\lambda_{n} \Phi\left(\delta_{n+1}\right)+\gamma_{n}
$$

for all $n \geq 0$, where $\lambda_{n} \in[0,1]$ with $\sum_{n=0}^{\infty} \lambda_{n}=\infty$ and $\gamma_{n}=o\left(\lambda_{n}\right)$. Then $\delta_{n} \rightarrow 0$ as $n \rightarrow \infty$.

\section{Main results}

Now, we give our main results in this paper.

Theorem 2.1 Let $E$ be a real Banach space, $D$ be a nonempty closed convex subset of $E$ and $T: D \rightarrow D$ be a uniformly L-Lipschitzian asymptotically pseudocontractive mapping with a sequence $\left\{k_{n}\right\} \subset[1,+\infty), \lim _{n \rightarrow \infty} k_{n}=1$ and $q \in F(T)=\{x \in D: T x=x\} \neq \emptyset$. Let $\left\{a_{n}\right\}$, $\left\{b_{n}\right\},\left\{c_{n}\right\}$ and $\left\{d_{n}\right\}$ be four real sequences in $[0,1]$ satisfying the following conditions:

$(\mathrm{A}-1) a_{n}, b_{n}, d_{n} \rightarrow 0$ as $n \rightarrow \infty$;

(A-2) $\sum_{n=1}^{\infty} a_{n}=\infty$;

(A-3) $c_{n}=o\left(a_{n}\right)$.

For some $x_{1} \in D$, let $\left\{x_{n}\right\}$ be a modified Ishikawa iterative sequence with errors defined by (1.4). Suppose that there exists a strictly increasing continuous function $\Phi:[0,+\infty) \rightarrow$ $[0,+\infty)$ with $\Phi(0)=0$ such that

$$
\left\langle T^{n} x-q, j(x-q)\right\rangle \leq k_{n}\|x-q\|^{2}-\Phi(\|x-q\|)
$$

for all $n \geq 1$, where $j(x-q) \in J(x-q)$. Then $\left\{x_{n}\right\}$ converges strongly to the fixed point $q$ of $T$. 
Proof Step 1. For any $n \geq 1,\left\{x_{n}\right\}$ is a bounded sequence.

Set $\sup \left\{k_{n}: n \geq 1\right\}=k$. Then there exists $x_{1} \in D$ with $x_{1} \neq T x_{1}$ such that $r_{0}=(k+L) \| x_{1}-$ $q \|^{2} \in R(\Phi)$. Indeed, for any taking $x_{1} \in D$ and $x_{1} \neq T x_{1}$, we denote $r_{0}=(k+L)\left\|x_{1}-q\right\|^{2}$. If $\Phi(r) \rightarrow+\infty$ as $r \rightarrow+\infty$, then $r_{0} \in R(\Phi)$. If $\sup \{\Phi(r): r \in[0,+\infty)\}=r_{1}<+\infty$ with $r_{1}<r_{0}$, then there exists a sequence $\left\{\xi_{n}\right\} \subset D$ such that $\xi_{n} \rightarrow q$ as $n \rightarrow \infty$ with $\xi_{n} \neq q$, thus there exists a positive integer $n_{0}$ such that $(k+L)\left\|\xi_{n}-q\right\|^{2}<\frac{r_{1}}{2}$ for all $n \geq n_{0}$. We redefine $x_{1}=\xi_{n_{0}}$ and $(k+L)\left\|x_{1}-q\right\|^{2} \in R(\Phi)$.

Set $R=\Phi^{-1}\left(r_{0}\right)$. Then we obtain $\left\|x_{1}-q\right\| \leq R$. Denote

$$
\begin{aligned}
& B_{1}=\{x \in D:\|x-q\| \leq R\}, \quad B_{2}=\{x \in D:\|x-q\| \leq 2 R\}, \\
& M=\sup _{n}\left\{\left\|u_{n}-q\right\|+\left\|v_{n}-q\right\|\right\} .
\end{aligned}
$$

Next, we prove that $x_{n} \in B_{1}$ for any $n \geq 1$. If $n=1$, then $x_{1} \in B_{1}$. Now, we assume that it holds for some $n$, i.e., $x_{n} \in B_{1}$. We prove that $x_{n+1} \in B_{1}$. Suppose that this does not hold. Then $\left\|x_{n+1}-q\right\|>R$. Now, we denote

$$
\tau_{0}=\min \left\{1, \frac{R}{2 L R+M}, \frac{\Phi(R)}{10 R^{2}}, \frac{\Phi(R)}{10 M R}, \frac{\Phi(R)}{10 R\left[2 L R+3 L^{2} R+2 L(M+R)\right]}\right\} .
$$

Since $a_{n}, b_{n}, c_{n}, \frac{c_{n}}{a_{n}}, d_{n}, k_{n}-1 \rightarrow 0$ as $n \rightarrow \infty$, without loss of generality, let $0 \leq a_{n}, b_{n}, c_{n}, \frac{c_{n}}{a_{n}}$, $d_{n}, k_{n}-1 \leq \tau_{0}$ for any $n \geq 1$. Thus, we have

$$
\begin{aligned}
\left\|y_{n}-q\right\| & \leq\left(1-b_{n}-d_{n}\right)\left\|x_{n}-q\right\|+b_{n}\left\|T^{n} x_{n}-T^{n} q\right\|+d_{n}\left\|v_{n}-q\right\| \\
& \leq\left(1-b_{n}-d_{n}+b_{n} L\right)\left\|x_{n}-q\right\|+d_{n} M \\
& \leq\left(1+b_{n} L\right) R+d_{n} M \\
& \leq R+\tau_{0}(L R+M) \\
& <2 R, \\
\left\|x_{n+1}-q\right\| & \leq\left(1-a_{n}-c_{n}\right)\left\|x_{n}-q\right\|+a_{n}\left\|T^{n} y_{n}-T^{n} q\right\|+c_{n}\left\|u_{n}-q\right\| \\
& \leq\left\|x_{n}-q\right\|+a_{n} L\left\|y_{n}-q\right\|+c_{n}\left\|u_{n}-q\right\| \\
& \leq R+a_{n} L\left[\left(1+b_{n} L\right) R+d_{n} M\right]+c_{n} M \\
& \leq R+2 a_{n} L R+c_{n} M \\
& \leq R+\tau_{0}(2 L R+M) \\
& \leq 2 R
\end{aligned}
$$

and

$$
\begin{aligned}
& \left\|T^{n} x_{n+1}-T^{n} y_{n}\right\| \\
& \leq L\left\|x_{n+1}-y_{n}\right\| \\
& \leq a_{n} L\left\|T^{n} y_{n}-x_{n}\right\|+c_{n} L\left\|u_{n}-x_{n}\right\|+b_{n} L\left\|x_{n}-T^{n} x_{n}\right\|+d_{n} L\left\|x_{n}-v_{n}\right\| \\
& \leq a_{n} L\left(\left\|x_{n}-q\right\|+\left\|T^{n} y_{n}-T^{n} q\right\|\right)+c_{n} L\left(\left\|u_{n}-q\right\|+\left\|x_{n}-q\right\|\right) \\
& \quad+b_{n} L\left(\left\|x_{n}-q\right\|+\left\|T^{n} x_{n}-T^{n} q\right\|\right)+d_{n} L\left(\left\|v_{n}-q\right\|+\left\|x_{n}-q\right\|\right)
\end{aligned}
$$




$$
\begin{aligned}
& \leq a_{n} L\left(\left\|x_{n}-q\right\|+L\left\|y_{n}-q\right\|\right)+c_{n} L(M+R)+b_{n} L(1+L)\left\|x_{n}-q\right\|+d_{n} L(M+R) \\
& \leq a_{n} L(1+2 L) R+c_{n} L(M+R)+b_{n} L(1+L) R+d_{n} L(M+R) \\
& \leq \tau_{0}[L(1+2 L) R+L(M+R)+L(1+L) R+L(M+R)] \\
& \leq \tau_{0}\left[2 L R+3 L^{2} R+2 L(M+R)\right] \\
& \leq \frac{\Phi(R)}{10 R} .
\end{aligned}
$$

Applying Lemma 1.7 and the formulas above, we obtain

$$
\begin{aligned}
\left\|x_{n+1}-q\right\|^{2}= & \left\|\left(1-a_{n}-c_{n}\right)\left(x_{n}-q\right)+a_{n}\left(T^{n} y_{n}-q\right)+d_{n}\left(u_{n}-q\right)\right\|^{2} \\
\leq & \left(1-a_{n}\right)^{2}\left\|x_{n}-q\right\|^{2}+2 a_{n}\left\langle T^{n} y_{n}-q, j\left(x_{n+1}-q\right)\right\rangle+2 c_{n}\left\langle u_{n}-q, j\left(x_{n+1}-q\right)\right\rangle \\
= & \left(1-a_{n}\right)^{2}\left\|x_{n}-q\right\|^{2}+2 a_{n}\left\langle T^{n} x_{n+1}-q, j\left(x_{n+1}-q\right)\right\rangle \\
& +2 a_{n}\left\langle T^{n} y_{n}-T^{n} x_{n+1}, j\left(x_{n+1}-q\right)\right\rangle+2 c_{n}\left\langle u_{n}-q, j\left(x_{n+1}-q\right)\right\rangle \\
\leq & \left(1-a_{n}\right)^{2}\left\|x_{n}-q\right\|^{2}+2 a_{n}\left[k_{n}\left\|x_{n+1}-q\right\|^{2}-\Phi\left(\left\|x_{n+1}-q\right\|\right)\right] \\
& +2 a_{n}\left\|T^{n} x_{n+1}-T^{n} y_{n}\right\| \cdot\left\|x_{n+1}-q\right\|+2 c_{n}\left\|u_{n}-q\right\| \cdot\left\|x_{n+1}-q\right\| \\
\leq & \left(1-a_{n}\right)^{2} R^{2}+2 a_{n}\left[k_{n}\left\|x_{n+1}-q\right\|^{2}-\Phi(R)\right]+\frac{2 a_{n}}{10 R} \Phi(R) 2 R+4 c_{n} M R \\
\leq & \left(1-a_{n}\right)^{2} R^{2}+2 a_{n}\left[k_{n}\left\|x_{n+1}-q\right\|^{2}-\Phi(R)\right]+\frac{4 a_{n}}{5} \Phi(R) .
\end{aligned}
$$

Since $a_{n} \rightarrow 0$ and $k_{n} \rightarrow 1$ as $n \rightarrow \infty$, we have $2 k_{n} a_{n} \rightarrow 0$ as $n \rightarrow \infty$. Thus, without loss of generality, let $1-2 k_{n} a_{n}>0$ for any $n \geq 1$. Then (2.6) implies that

$$
\begin{aligned}
& \left\|x_{n+1}-q\right\|^{2} \\
& \quad \leq R^{2}+\frac{2 a_{n}}{1-2 k_{n} a_{n}}\left[\left(k_{n}-1\right)+\frac{a_{n}}{2}\right] R^{2}-\frac{2 a_{n}}{1-2 k_{n} a_{n}} \Phi(R)+\frac{2 a_{n}}{1-2 k_{n} a_{n}}\left[\frac{2}{5} \Phi(R)\right] \\
& \quad \leq R^{2}-\frac{2 a_{n}}{5\left(1-2 k_{n} a_{n}\right)} \Phi(R) \\
& \quad \leq R^{2}
\end{aligned}
$$

which is a contradiction. Hence, $x_{n+1} \in B_{1}$, i.e., $\left\{x_{n}\right\}$ is a bounded sequence.

Step 2. We prove that $\left\|x_{n}-q\right\| \rightarrow 0$ as $n \rightarrow \infty$.

By Step 1 , we obtain $\left\{\left\|x_{n}-q\right\|\right\}$ is a bounded sequence and so is $\left\{\left\|y_{n}-q\right\|\right\}$. Let

$$
M_{0}=\sup _{n}\left\{\left\|x_{n}-q\right\|\right\}+\sup _{n}\left\{\left\|y_{n}-q\right\|\right\}+\sup _{n}\left\{\left\|u_{n}-q\right\|\right\}+\sup _{n}\left\{\left\|v_{n}-q\right\|\right\} .
$$

Observe that

$$
\begin{aligned}
\left\|x_{n+1}-y_{n}\right\| \leq & a_{n} L\left\|T^{n} y_{n}-x_{n}\right\|+c_{n} L\left\|u_{n}-x_{n}\right\|+b_{n} L\left\|x_{n}-T^{n} x_{n}\right\|+d_{n} L\left\|x_{n}-v_{n}\right\| \\
\leq & a_{n} L\left(\left\|x_{n}-q\right\|+\left\|T^{n} y_{n}-T^{n} q\right\|\right)+c_{n} L\left(\left\|u_{n}-q\right\|+\left\|x_{n}-q\right\|\right) \\
& +b_{n} L\left(\left\|x_{n}-q\right\|+\left\|T^{n} x_{n}-T^{n} q\right\|\right)+d_{n} L\left(\left\|v_{n}-q\right\|+\left\|x_{n}-q\right\|\right) \\
\leq & \left(a_{n}+b_{n}\right) L(1+L) M_{0}+\left(c_{n}+d_{n}\right) L M_{0} .
\end{aligned}
$$


Using Lemma 1.7, (2.6) and (2.8), we have

$$
\begin{aligned}
&\left\|x_{n+1}-q\right\|^{2} \\
& \leq\left(1-a_{n}-c_{n}\right)^{2}\left\|x_{n}-q\right\|^{2}+2 a_{n}\left\langle T^{n} y_{n}-q, j\left(x_{n+1}-q\right)\right\rangle+2 c_{n}\left\langle u_{n}-q, j\left(x_{n+1}-q\right)\right\rangle \\
& \leq\left(1-a_{n}\right)^{2}\left\|x_{n}-q\right\|^{2}+2 a_{n}\left\langle T^{n} x_{n+1}-q, j\left(x_{n+1}-q\right)\right\rangle \\
&+2 a_{n}\left\langle T^{n} y_{n}-T^{n} x_{n+1}, j\left(x_{n+1}-q\right)\right\rangle+2 c_{n}\left\langle u_{n}-q, j\left(x_{n+1}-q\right)\right\rangle \\
& \leq\left(1-a_{n}\right)^{2}\left\|x_{n}-q\right\|^{2}+2 a_{n}\left[k_{n}\left\|x_{n+1}-q\right\|^{2}-\Phi\left(\left\|x_{n+1}-q\right\|\right)\right] \\
&+2 a_{n}\left\|T^{n} x_{n+1}-T^{n} y_{n}\right\| \cdot\left\|x_{n+1}-q\right\|+2 c_{n}\left\|u_{n}-q\right\| \cdot\left\|x_{n+1}-q\right\| \\
& \leq\left\|x_{n}-q\right\|^{2}+2 a_{n}\left(k_{n}-1\right) M_{0}^{2}+a_{n}^{2} M_{0}^{2}-a_{n} \Phi\left(\left\|x_{n+1}-q\right\|\right) \\
&+2 a_{n} L\left\|x_{n+1}-y_{n}\right\| M_{0}+2 c_{n} M_{0}^{2} \\
& \leq\left\|x_{n}-q\right\|^{2}+2 a_{n}\left(k_{n}-1\right) M_{0}^{2}+a_{n}^{2} M_{0}^{2}-a_{n} \Phi\left(\left\|x_{n+1}-q\right\|\right) \\
&+2 a_{n} L\left[\left(a_{n}+b_{n}\right) L(1+L) M_{0}+\left(c_{n}+d_{n}\right) L M_{0}\right] M_{0}+2 c_{n} M_{0}^{2} \\
& \leq\left\|x_{n}-q\right\|^{2}-a_{n} \Phi\left(\left\|x_{n+1}-q\right\|\right)+A_{n},
\end{aligned}
$$

where

$$
A_{n}=2 a_{n}\left(k_{n}-1\right) M_{0}^{2}+a_{n}^{2} M_{0}^{2}+2 a_{n} L\left[\left(a_{n}+b_{n}\right) L(1+L) M_{0}+\left(c_{n}+d_{n}\right) L M_{0}\right] M_{0}+2 c_{n} M_{0}^{2} .
$$

Let $\delta_{n}=\left\|x_{n}-q\right\|^{2}, \lambda_{n}=a_{n}$ and $\gamma_{n}=A_{n}$. Then (2.9) leads to

$$
\delta_{n+1}^{2} \leq \delta_{n}^{2}-\lambda_{n} \Phi\left(\delta_{n+1}\right)+\gamma_{n} .
$$

Therefore, by Lemma 1.8, we obtain $\lim _{n \rightarrow \infty} \delta_{n}=0$, i.e., $x_{n} \rightarrow q$ as $n \rightarrow \infty$. This completes the proof.

From Theorem 2.1, we have the following corollary.

Corollary 2.2 Let E be a real Banach space. Let D be a nonempty closed convex subset of $E, T: D \rightarrow D$ be a uniformly L-Lipschitzian asymptotically pseudocontractive mapping with a sequence $\left\{k_{n}\right\} \subset[1,+\infty), \lim _{n \rightarrow \infty} k_{n}=1$ and $q \in F(T)$. Let $\left\{a_{n}\right\}$ and $\left\{c_{n}\right\}$ be two real sequences in $[0,1]$ satisfying the following conditions:

(A-1) $a_{n} \rightarrow 0$ as $n \rightarrow \infty$;

(A-2) $\sum_{n=1}^{\infty} a_{n}=\infty$;

(A-3) $c_{n}=o\left(a_{n}\right)$.

For some $x_{1} \in D$, let $\left\{x_{n}\right\}$ be a modified Mann iterative sequence with errors defined by (1.5). Suppose that there exists a strictly increasing function $\Phi:[0,+\infty) \rightarrow[0,+\infty)$ with $\Phi(0)=0$ such that

$$
\left\langle T^{n} x-q, j(x-q)\right\rangle \leq k_{n}\|x-q\|^{2}-\Phi(\|x-q\|)
$$

for all $n \geq 1$, where $j(x-q) \in J(x-q)$. Then $\left\{x_{n}\right\}$ converges strongly to the fixed point $q$ of $T$. 
Proof In Theorem 2.1, letting $b_{n}=0, d_{n}=0$, we can get the convergence of the modified Mann iteration (1.5).

Theorem 2.3 Let E be a real Banach space. Let D be a nonempty closed convex subset of $E$ and $T_{i}: K \rightarrow K$ be two uniformly $L_{i}$-Lipschitzian mappings with $q \in F\left(T_{1}\right) \cap F\left(T_{2}\right)$. Let $\left\{k_{n}\right\} \subset[1,+\infty)$ be a sequence with $k_{n} \rightarrow 1$ as $n \rightarrow \infty$. Let $\left\{a_{n}\right\},\left\{b_{n}\right\},\left\{c_{n}\right\}$ and $\left\{d_{n}\right\}$ be four real sequences in $[0,1]$ satisfying the following conditions:

(A-1) $a_{n}, b_{n} \rightarrow 0$ as $n \rightarrow \infty$;

(A-2) $\sum_{n=1}^{\infty} a_{n}=\infty$;

$(\mathrm{A}-3) c_{n}=o\left(a_{n}\right), d_{n} \rightarrow 0$ as $n \rightarrow \infty$.

For some $x_{1} \in D$, let $\left\{x_{n}\right\}$ be an iterative sequence with errors defined by

$$
\left\{\begin{array}{l}
y_{n}=\left(1-b_{n}-d_{n}\right) x_{n}+b_{n} T_{1}^{n} x_{n}+d_{n} v_{n} \\
x_{n+1}=\left(1-a_{n}-c_{n}\right) x_{n}+a_{n} T_{2}^{n} y_{n}+c_{n} u_{n}
\end{array}\right.
$$

for all $n \geq 1$. Suppose that there exists a strictly increasing function $\Phi:[0,+\infty) \rightarrow[0,+\infty)$ with $\Phi(0)=0$ such that

$$
\left\langle T_{i}^{n} x-q, j(x-q)\right\rangle \leq k_{n}\|x-q\|^{2}-\Phi(\|x-q\|)
$$

for all $n \geq 1$ and $i=1,2$, where $j(x-q) \in J(x-q)$. Then $\left\{x_{n}\right\}$ converges strongly to the fixed point $q$ of $T_{1} \cap T_{2}$.

Proof Similarly, we can obtain the result of Theorem 2.3 by using the proof method of Theorem 2.1.

Remark 2.4 Theorem 2.1 extends, improves and unifies Theorems 3.1, 3.2, 3.3 of [13] and Theorem 3.5 of [14] in the following sense:

(1) The modified Mann iteration and modified Ishikawa iteration are replaced by the modified Ishikawa iteration with errors introduced by $\mathrm{Xu}$ [17].

(2) The proof method of Theorem 2.1 is quite different from the method of [13, 14].

(3) In [13], the author did not require the function $\Phi$ to be surjective. Since $x_{0}$ is an arbitrary point chosen in $D$, it is possible that $\Phi^{-1}\left(a_{0}\right)$ is not well defined.

(4) The conditions $\sum_{n=0}^{\infty} \alpha_{n}^{2}<\infty, \sum_{n=0}^{\infty} \alpha_{n}\left(k_{n}-1\right)<\infty, \sum_{n=0}^{\infty} \beta_{n}<\infty$ in [13, Theorem 3.1, Theorem 3.2] and [14, Theorem 2.1] are replaced by the more general conditions $\alpha_{n}, \beta_{n} \rightarrow 0$ as $n \rightarrow \infty$. Also, the conditions $\sum_{n \geq 0}\left(b_{n}+c_{n}\right)^{2}<\infty$, $\sum_{n \geq 0}\left(b_{n}+c_{n}\right)\left(k_{n}-1\right)<\infty, \sum_{n \geq 0} c_{n}<\infty$ in [13, Theorem 3.3] are replaced by $b_{n} \rightarrow 0$ as $n \rightarrow \infty$ and $c_{n}=o\left(b_{n}\right)$ of Corollary 2.2.

Remark 2.5 A mapping $T$ is said to be weak uniformly Lipschitzian if there exists a constant $L>0$ such that

$$
\left\|T^{n} x-T^{n} y\right\| \leq L\|x-y\|
$$

for all $n \geq 1, x \in D$ and $y \in F(T)$. Then, using the same methods, we can also prove that Theorem 2.1 holds for the more general class of weak uniformly Lipschitzian asymptotically pseudocontractive mappings. In practical application, it can be seen from the following example. 
Example 2.6 Let $E=\Re$ be the set of real numbers with the usual norm and $D=[0,+\infty)$. Define a mapping $T: D \rightarrow D$ by

$$
T x=\frac{x^{3}}{1+x^{2}}
$$

for all $x \in D$. Then $T$ has a fixed point $q=0 \in D$ and $T$ is a strictly monotone increasing mapping. Thus, $T x \leq x$ for any $x \in D$, which implies that $T^{n} x \leq T^{n-1} x \leq \cdots \leq T x$. Define a function $\Phi:[0,+\infty) \rightarrow[0,+\infty)$ by $\Phi(t)=\frac{t^{2}}{1+t^{2}}$. Then $\Phi$ is a strictly increasing continuous function with $\Phi(0)=0$. For all $x \in D$ and $q \in F(T)$, if $k_{n}=1$ and $L=1$, then we obtain

$$
\begin{aligned}
\left\langle T^{n} x-T^{n} q, j(x-q)\right\rangle & =\left\langle T^{n} x-0, j(x-0)\right\rangle \\
& =\left\langle T^{n} x, x\right\rangle \\
& \leq\langle T x, x\rangle \\
& =\left\langle\frac{x^{3}}{1+x^{2}}, x\right\rangle \\
& =\frac{x^{4}}{1+x^{2}} \\
& =k_{n}|x-q|^{2}-\frac{|x-q|^{2}}{1+|x-q|^{2}} \\
& =k_{n}|x-q|^{2}-\Phi(|x-q|)
\end{aligned}
$$

and

$$
\begin{aligned}
\left|T^{n} x-T^{n} q\right| & =\left|T^{n} x-0\right| \\
& \leq|T x-0| \\
& =\left|\frac{x^{3}}{1+x^{2}}-0\right| \\
& \leq|x-0| \\
& \leq L|x-q| .
\end{aligned}
$$

Therefore, $T$ is weakly uniform Lipschitzian and satisfies (2.1) of Theorem 2.1.

\section{Competing interests}

The authors declare that they have no competing interests.

\section{Authors' contributions}

All authors contributed equally in writing this paper and read and approved the final manuscript.

\section{Acknowledgements}

The authors are grateful to Professor Yeol-Je Cho for valuable suggestions which helped to improve the manuscript. The first author was supported by Hebei Provincial Natural Science Foundation (Grant No. A2011210033).

Received: 19 August 2012 Accepted: 13 January 2013 Published: 28 February 2013

\section{References}

1. Goebel, K, Kirk, WA: A fixed point theorem for asymptotically nonexpansive mappings. Proc. Am. Math. Soc. 35 $171-174(1972)$ 
2. Schu, J: Iterative construction of fixed point of asymptotically nonexpansive mappings. J. Math. Anal. Appl. 158, 407-413 (1991)

3. Chang, SS, Cho, YJ, Zhou, HY: Iterative Methods for Nonlinear Operator Equations in Banach Spaces. Nova Science Publishers, New York (2002)

4. Cho, YJ, Hussain, N, Pathak, HK: Approximation of nearest common fixed points of asymptotically I-nonexpansive mappings in Banach spaces. Commun. Korean Math. Soc. 26, 483-498 (2011)

5. Cho, YJ, Kang, SM, Qin, X: Strong convergence of an implicit iterative process for an infinite family of strict pseudocontractions. Bull. Korean Math. Soc. 47, 1259-1268 (2010)

6. Cho, YJ, Kim, JK, Lan, HY: Three step procedure with errors for generalized asymptotically quasi-nonexpansive mappings in Banach spaces. Taiwan. J. Math. 12, 2155-2178 (2008)

7. Guo, W, Cho, YJ: On the strong convergence of the implicit iterative processes with errors for a finite family of asymptotically nonexpansive mappings. Appl. Math. Lett. 21, 1046-1052 (2008)

8. Hussain, N: Asymptotically pseudo-contractions, Banach operator pairs and best simultaneous approximations. Fixed Point Theory Appl. 2011, Article ID 812813 (2011)

9. Qin, X, Cho, YJ, Shang, M: Convergence analysis of implicit iterative algorithms for asymptotically nonexpansive mappings. Appl. Math. Comput. 219, 542-550 (2009)

10. Qin, X, Cho, YJ, Kang, SM, Zhou, H: Convergence of a modified Halpern-type iteration algorithm for quasi- $\phi$-nonexpansive mappings. Appl. Math. Lett. 22, 1051-1055 (2009)

11. Zhou, HY, Cho, YJ, Kang, SM: A new iterative algorithm for approximating common fixed points for asymptotically nonexpansive mappings. Fixed Point Theory Appl. 2007, Article ID 64974 (2007)

12. Chang, SS: Some results for asymptotically pseudocontractive mappings and asymptotically nonexpansive mappings. Proc. Am. Math. Soc. 129, 845-853 (2001)

13. Ofoedu, EU: Strong convergence theorem for uniformly L-Lipschitzian asymptotically nonexpansive mapping in Banach space. J. Math. Anal. Appl. 321, $722-728$ (2006)

14. Chang, SS, Cho, YJ, Kim, JK: Some results for uniformly L-Lipschitzian mappings in Banach spaces. Appl. Math. Lett. 22, 121-125 (2009)

15. Cho, YJ, Qin, X, Kang, SM: Strong convergence of the modified Halpern-type iteration algorithms in Banach spaces. An. St. Univ. Ovidius Constanta, Ser. Mat. 17, 51-68 (2009)

16. Yao, Y, Cho, YJ: A strong convergence of a modified Krasnoselskii-Mann method for non-expansive mappings in Hilbert spaces. Math. Model. Anal. 15, 265-274 (2010)

17. Xu, YG: Ishikawa and Mann iterative processes with errors for nonlinear strongly accretive operator equations. J. Math. Anal. Appl. 224, 91-101 (1998)

18. Deimling, K: Nonlinear Functional Analysis. Springer, Berlin (1980)

19. Moore, C, Nnoli, BVC: Iterative solution of nonlinear equations involving set valued uniformly accretive operators. Comput. Math. Appl. 42, 131-140 (2001)

doi:10.1186/1029-242X-2013-79

Cite this article as: Xue and Lv: Strong convergence theorems for uniformly L-Lipschitzian asymptotically pseudocontractive mappings in Banach spaces. Journal of Inequalities and Applications 2013 2013:79.

\section{Submit your manuscript to a SpringerOpen ${ }^{\circ}$ journal and benefit from:}

- Convenient online submission

- Rigorous peer review

- Immediate publication on acceptance

- Open access: articles freely available online

- High visibility within the field

- Retaining the copyright to your article 